\title{
APPLICATION OF AMMONIACAL SOLUTIONS FOR LEACHING AND ELECTROCHEMICAL DISSOLUTION OF METALS FROM ALLOYS PRODUCED FROM LOW-GRADE E-SCRAP
}

\begin{abstract}
Paper reports results of the research on the application of ammoniacal solutions (sulfate, chloride, carbonate) for hydrometallurgical treatment of smelted low-grade e-waste. Two $\mathrm{Cu}-\mathrm{Zn}-\mathrm{Sn}-\mathrm{Ag}-\mathrm{Pb}$ alloys were analyzed in details and discussed. Leaching of copper from the alloys was slow in sulfate solution, but the dissolution rate decreased in chloride and carbonate baths. Anodic alloys dissolution was uniform in sulfate and carbonate electrolytes, but high degradation of the material was observed in chloride bath. Chemical and phase composition of slimes and cathodic deposits produced during electrolysis were characterized. In all cases, separation of copper from other metals was found, but efficiencies of the processes were low.
\end{abstract}

Keywords: alloy; electrolysis; leaching; recovery; e-scrap

\section{Introduction}

Large amounts of valuable metals accumulated in secondary materials gave rise to a global trend called "urban mining" [1]. Recently, United Nations University reported [2] that annual worldwide generation solely waste electronic and electric equipment (WEEE) exceeded 40 million tonnes worth 52 billion USD, although it is expected that e-waste stream will reach 50 million tonnes by 2018. It has to be noted that accurate estimation of WEEE generation [3], its global transport [4] and recyclability [5] is difficult, mainly due to a lack of high quality data referred to world and domestic markets and economic dynamics.

In the current practice electronic waste is recycled mainly using pyrometallurgical methods [6,7], but various hydrometallurgical procedures were also proposed [6-8]. The latter are usually based on the direct treatment of waste electronic parts using acid leachants, while complexing alkaline solutions were investigated to a lesser extent [8]. Among them ammonia solutions were used, mainly for selective dissolution of copper and other metal ions (e.g. nickel, zinc) in carbonate, sulfate, chloride baths [9-11] or gold and silver in thiosulfate baths [12-14]. High purity copper was then recovered by electrowinning from $\mathrm{Cu}(\mathrm{I})$ or $\mathrm{Cu}(\mathrm{II})$ ammoniacal baths [15-17].

This paper is focused on the investigation of the copper recovery from low-grade electronic and electric waste, containing no gold, platinum or palladium. A combined method was used: mechanical separation of the metallic parts from the main stream of plastics, melting of the rich metallic phase and dissolution of the obtained alloys in ammoniacal systems. Depending on the type of the WEEE origin a range of alloys can be obtained [1824]. In the previous papers [22-24], smelted scraps were leached in ammoniacal solutions to dissolve copper via autocatalytic reaction [18,22,23] or anodically dissolved in acidic electrolytes [23-25]. In the current work ammoniacal systems were examined for both spontaneous and electrochemical dissolution of two other alloys of different compositions. A comparison of the results obtained in the present and former research can allow to determine general behavior of the individual metals and alloy phases in various baths and to select the most suitable system for the recovery of copper from smelted e-waste.

\section{Experimental}

Random waste computer boards and printed circuit boards of mobile phones from an urban scrap heap were collected, then crushed using industrial equipment and finally pyrometallurgically treated (without any additives or any special atmosphere) for one hour in an industrial chamber furnace (at $9 \mathrm{~kW}$ ) to remove remaining non-metallic compounds. In this study, two separate scraps portions (each about $16 \mathrm{~kg}$ ) of various electronic parts were treated thermally. Obtained ingots (each approx. $330 \mathrm{~g})$ were cut into rectangular samples $\left(\sim 15 \mathrm{~cm}^{2}\right)$. Structure of the alloys was observed under scanning electron microscope (Hitachi), analysis of the chemical composition was performed by energy dispersive spectroscopy (EDS) and phase analysis

\footnotetext{
AGH UNIVERSITY OF SCIENCE AND TECHNOLOGY, FACULTY OF NON - FERROUS METALS DEPARTMENT OF PHYSICAL CHEMISTRY AND METALLURGY OF NON-FERROUS METALS, AL. MICKIEWICZA 30, 30-059 KRAKOW, POLAND

\# Corresponding author: erudnik@agh.edu.pl
} 
was determined by X-ray diffractometry (Rikagu Mini Flex). General composition of the alloys was determined using X-ray fluorescence method (Rigaku Primini II).

Specimens of the alloys were leached or dissolved anodically $\left(\mathrm{i}_{\mathrm{A}}=3 \mathrm{~A} / \mathrm{dm}^{2}, \mathrm{i}_{\mathrm{C}}=1 \mathrm{~A} / \mathrm{dm}^{2}\right.$; two Pt cathodes $\left.50 \mathrm{~cm}^{2}\right)$ in ammoniacal solutions containing $1.5 \mathrm{M}\left(\mathrm{NH}_{3 \mathrm{aq}}+\mathrm{NH}_{4}{ }^{+}\right)$with $1 \mathrm{M}$ of suitable ammonium salts (chloride, carbonate, sulfate). Additional leaching series was performed using baths with $\mathrm{Cu}(\mathrm{II})$ ions addition $(50 \mathrm{mM}$, added as chloride, basic carbonate or sulfate). The alloy samples with refreshed surface (mechanical polishing with emery papers) were used in each experiment. Solution $\left(400 \mathrm{~cm}^{3}\right)$ was agitated with a magnetic stirrer at a rotation rate of $300 \mathrm{rpm}$. Electrode potential of the dissolved samples was monitored every 5 min using saturated calomel electrode (SCE) as a reference. Electrolysis voltage was also registered. Each dissolution series was carried out for $24 \mathrm{~h}$. All measurements were performed at ambient temperature $\left(20^{\circ} \mathrm{C}\right)$. Before and after measurement all samples were weighed. Slimes produced on the alloy surface as well as cathodic deposits were collected, washed, dried at the temperature of $60^{\circ} \mathrm{C}$ for $4 \mathrm{~h}$ and then weighed.

Samples $\left(2.5 \mathrm{~cm}^{3}\right)$ of the solutions were taken during the alloy dissolution, then diluted with $2 \mathrm{M} \mathrm{H}_{2} \mathrm{SO}_{4}$ and analyzed by atomic absorption spectrometry (AAS Solaar M5, ThermoElemental) to determine concentrations of metal ions. Weighted portions of the slimes and cathodic deposits were dissolved in hot $2 \mathrm{M} \mathrm{H}_{2} \mathrm{SO}_{4}$ with $\mathrm{H}_{2} \mathrm{O}_{2}$ addition and then analyzed by means of AAS. X-ray diffractometry was used for identification of the phase composition of the obtained solids.

a)

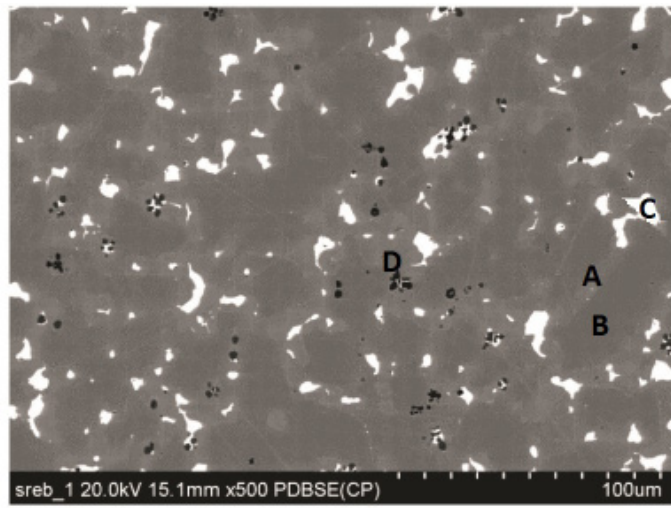

b)

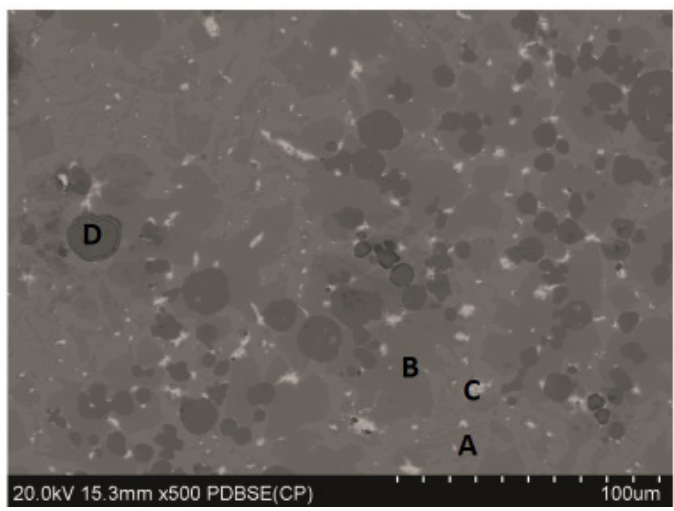

\section{Results and discussion}

\subsection{Characterization of alloys}

Pyrometallurgical treatment of e-waste enables formation of metallic alloys of increased concentrations of metals in comparison with the origin material [19-21]. In the present study two alloys were investigated. Alloy I consisted mainly of $69.0 \% \mathrm{Cu}$, $10.7 \% \mathrm{Zn}, 9.2 \% \mathrm{Sn}, 4.0 \% \mathrm{Ag}, 2.5 \% \mathrm{~Pb}, 2.3 \% \mathrm{Fe}, 0.1 \% \mathrm{Si}, 1.5 \%$ $\mathrm{Al}$ and $0.8 \% \mathrm{Ni}$. Alloy II contained the same elements, but their fractions were different: $47.8 \% \mathrm{Cu}, 3.3 \% \mathrm{Zn}, 17.6 \% \mathrm{Sn}, 0.1 \%$ $\mathrm{Ag}, 13.5 \% \mathrm{~Pb}, 10.2 \% \mathrm{Fe}, 2.8 \% \mathrm{Si}, 0.2 \% \mathrm{Al}, 0.8 \% \mathrm{Ni}$, and $0.3 \%$ $\mathrm{Mn}$. Both alloys contained also traces of $\mathrm{P}$ and $\mathrm{Cr}$ (below $0.1 \%$ ), while $\mathrm{Ca}(3.3 \%)$ and $\mathrm{Mo}(0.1 \%)$ were detected additionally in the alloy II. Comparison of the data with the composition of other alloys produced from WEEE [19-22] shows that dependently on the origin of the scrap high copper metallic material can be produced $(50-72 \% \mathrm{Cu})$. Tin contents in the smelted e-scrap can change from $2-3 \%[18,22]$ via $9-13 \%[19,24]$ up to $29 \%$ [20], whereas lead percentages are below $1 \%[21,23]$ or reach $9 \%[19$, $20]$. Total silver concentration in the alloys obtained from lowgrade e-waste is usually in the range 3-6\% [18, 22-24], but this element can be distributed among copper and tin/lead rich phases, depending on the heat treatment temperature [21]. Percentages of remaining metals like $\mathrm{Zn}, \mathrm{Ni}, \mathrm{Fe}, \mathrm{Al}$, Au or Pt are variable.

Differences in the elemental composition of the alloys result in some changes of their phase compositions. Fig. 1 shows morphology of the polished samples. It was observed that distribution of the individual phases was not uniform in
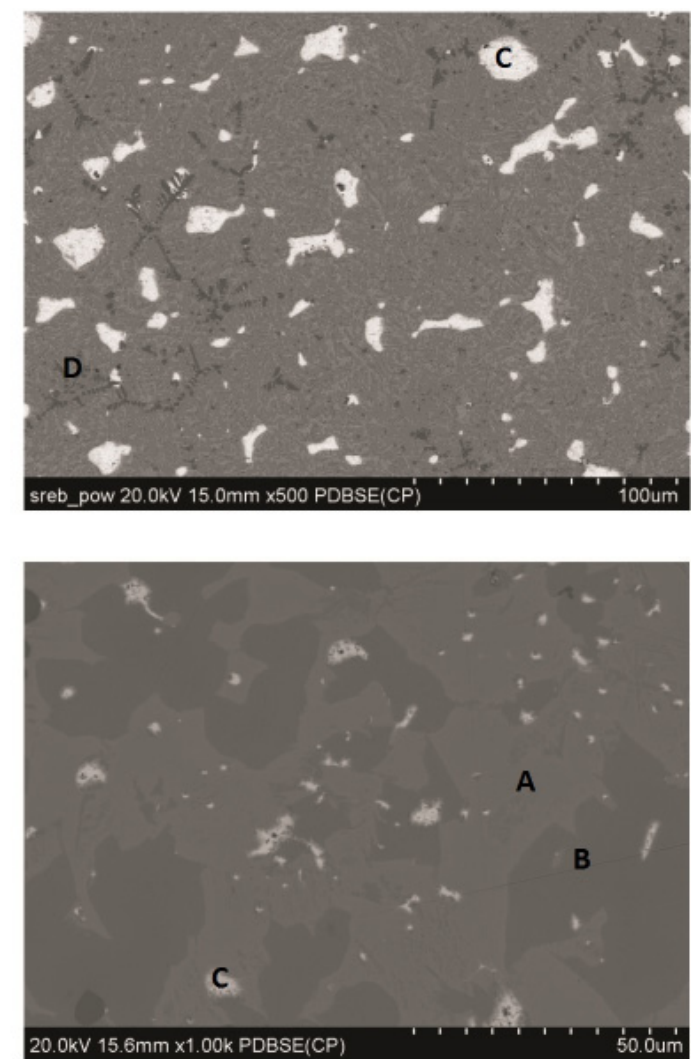

Fig. 1. Distribution of individual phases at various places of the alloy: a) I, b) II 
the whole bulk of the specimens due to various conditions of the melt cooling at the external and internal parts of the ingots. Five phases were observed in both materials, but their volume fractions (Fig. 1), distribution of elements (Fig. 2) and detailed elemental composition (Table 1) were totally different. Two copper-rich phases (A - light grey areas, $\mathrm{B}$ - dark grey areas) representing $\mathrm{Cu}-\mathrm{Zn}-\mathrm{Sn}-(\mathrm{Ag})$ systems were detected, but they were enriched in zinc (approx. 17\%) in the alloy I and in tin (11\% and $27 \%$, respectively) in the alloy II. White areas distributed randomly in the bulk of the alloys were lead-rich phase (phase C)
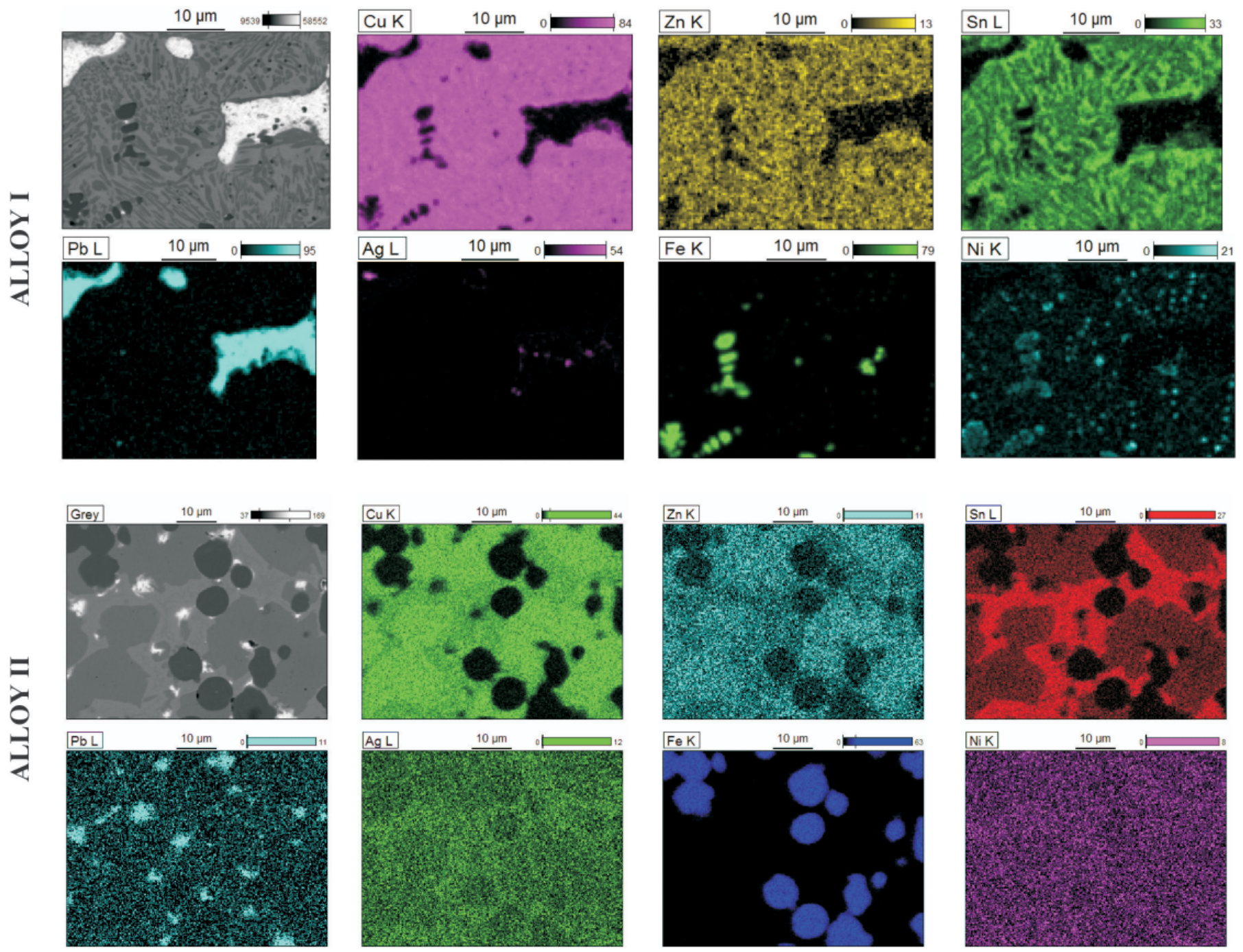

Fig. 2. Mapping analysis of the alloys

TABLE 1

Composition of the individual phases in the alloys

\begin{tabular}{|c|c|c|c|c|c|c|c|c|c|c|c|c|c|}
\hline \multirow{2}{*}{ Phase } & \multicolumn{13}{|c|}{ Average content, wt\% } \\
\hline & Al & Si & $\mathbf{P}$ & Fe & $\mathbf{N i}$ & $\mathbf{C u}$ & Zn & Ag & Sn & $\mathbf{P b}$ & $\mathrm{Cr}$ & Mn & Mo \\
\hline \multicolumn{14}{|c|}{ ALLOY I } \\
\hline A & 0.37 & & & 0.28 & 0.11 & 71.38 & 17.30 & 7.11 & 3.48 & & & & \\
\hline $\mathrm{B}$ & 0.24 & & & 0.72 & 0.12 & 78.37 & 16.85 & 3.08 & 0.64 & & & & \\
\hline $\mathrm{C}$ & 0.67 & & & & & 6.65 & 1.01 & 2.15 & 2.50 & 89.14 & & & \\
\hline $\mathrm{D}$ & & 6.20 & 0.44 & 86.03 & 0.78 & 4.70 & 0.87 & 0.22 & & & 0.89 & & \\
\hline $\mathrm{E}$ & & & & & & 6.82 & 3.85 & 80.49 & 8.76 & 0.09 & & & \\
\hline \multicolumn{14}{|c|}{ ALLOY II } \\
\hline A & & & & 0.50 & 0.79 & 68.55 & 2.38 & 0.45 & 26.96 & & & 0.38 & \\
\hline $\mathrm{B}$ & & & & 0.98 & 0.61 & 81.14 & 5.61 & & 11.39 & & & 0.23 & \\
\hline $\mathrm{C}^{*}$ & 0.37 & & & 0.66 & & 21.54 & 1.24 & 1.36 & 8.20 & 68.31 & & & \\
\hline $\mathrm{D}$ & & 2.73 & 0.16 & 88.96 & 1.18 & 5.99 & & & 0.40 & & 0.40 & 0.22 & 0.35 \\
\hline
\end{tabular}

* Phase $\mathrm{E}$ was observed inside phase $\mathrm{C}$, but it was not analyzed due to too small sizes of the inclusions (low accuracy caused by detection of signals from neighborhood). 
contaminated mainly by copper and tin. Dendritic or oval black precipitates were iron-rich phase (phase D) with some copper and silicon corresponding to steel residue. Small grey silver-rich inclusions were observed inside the phase $\mathrm{C}$.

Comparison of the above data with the morphology of the alloys reported in other papers $[19,20,22]$ confirms formation of copper-based matrix with tin and lead-rich phases separated out from the high copper phase. Steel fraction remains as randomly distributed inclusions [19,22].

Figure 3 shows diffraction patterns of the alloys. It was observed that despite different composition of the alloys similar phases were detected. Main constituents identified were brass, lead, steel as well as $\mathrm{Cu}-\mathrm{Sn}$ and Ag-Sn intermetallic compounds. A review of the literature data showed that no direct XRD analysis of the smelted e-scrap was performed. The authors described the phases on the basis of binary or ternary equilibrium diagrams [19,20]. Regardless of that the results are quite consistent. For example, Groot and van der Linde [19] reported the presence of two ( $\alpha$ and $\delta$ ) bronze phases and lead inclusions $(88 \% \mathrm{~Pb})$. Similarly to the current study, no equilibrium $\mathrm{Cu}_{3} \mathrm{Sn}$ intermetallic compound was found. The authors supposed that it could not form during faster cooling to room temperature due to its low transformation temperature (about $350^{\circ} \mathrm{C}$ ). Cayumil et al. [20] confirmed that melting of printed circuit boards (PCBs) at $1150^{\circ} \mathrm{C}$ led to the formation of separated copper-rich and tin-rich metallic droplets. The microstructure of both types of droplets was lamellar and alternating layers of tin-rich, lead-rich and copper-rich phases were found. It was concluded that lead with tin form a solid solution with a limited solubility, but lead-rich phase tends to get separated from copper-based phase due to very low affinity of lead with copper. In turn, tin with higher affinity with copper needed to separate from copper after $20 \mathrm{~min}$ of the heat treatment, but tin's phase separation was observed after $10 \mathrm{~min}$ of the heat treatment in tin-rich phase at lower quenching temperature. Significant proportions of $\mathrm{Ag}, \mathrm{Au}, \mathrm{Pd}$ and $\mathrm{Pt}$ were found concentrated within two types of metallic phases [21], but particular intermetallic compounds were not indicated in both cases.

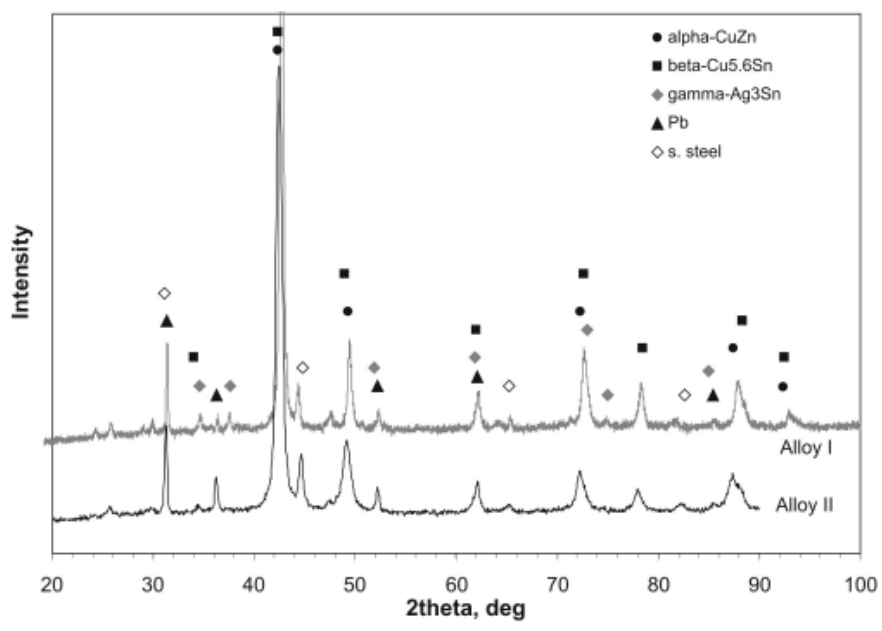

Fig. 3. X-ray diffraction patterns of the alloys
Finally, it should be noted that independently on the method used for the heat treatment of the e-scrap, the main problem is removal the plastics parts. Pyrolysis, combustion and smelting $[20,21,26,27]$ were found useful for thermal decomposition of polymers, but it is often accompanied by emission of toxic organic compounds [26,27]. Application of an inert atmosphere can prevent the burning of carbon from polymers, thereby significantly reducing the generation of greenhouse gas emissions during waste recycling [20,21]. Some information [20] suggests using temperatures above $1100^{\circ} \mathrm{C}$ for thermal processing of waste PCBs to serious decrease of harmful gases evolution. In the current study, pyrometallurgical treatment of the e-scrap was carried out at constant furnace power $(9 \mathrm{~kW})$, but temperature inside the installation was not monitored. Gaseous products also were not collected, thus their chemical analysis was not performed. Therefore, detailed comparison of the thermal waste processing with the literature data requires further considerations.

\subsection{Leaching of alloys}

Both alloys were leached in ammoniacal solutions of various compositions. Additional series was performed in the baths containing intentionally $\mathrm{Cu}$ (II) ions to enhance selective and spontaneous dissolution of copper via autocatalytic reaction:

$$
\mathrm{Cu}+\mathrm{Cu}\left(\mathrm{NH}_{3}\right)_{4}{ }^{2+} \rightarrow 2 \mathrm{Cu}\left(\mathrm{NH}_{3}\right)_{2}{ }^{+}
$$

Table 2 compiles mass losses of the alloys obtained in the experiments. It was observed that sulfate baths were not effective for leaching as two other systems. Moreover, addition of copper ions improved dissolution of metals only from the alloy II and solely for chloride and carbonate solutions.

TABLE 2

Mass losses of the alloys after leaching and anodic dissolution for $24 \mathrm{~h}$

\begin{tabular}{|c|c|c|c|c|c|}
\hline \hline \multirow{2}{*}{ Dissolution } & \multirow{2}{*}{ Alloy } & \multirow{2}{*}{$\begin{array}{c}\text { Initial } \\
\text { Cu(II) } \\
\end{array}$} & & \multicolumn{3}{|c|}{ Mass loss of the alloy, $\mathbf{~ m g / \mathbf { c m } ^ { 2 }}$} \\
\cline { 3 - 6 } & & $\begin{array}{c}\text { Sulfate } \\
\text { bath }\end{array}$ & $\begin{array}{c}\text { Chloride } \\
\text { bath }\end{array}$ & $\begin{array}{c}\text { Carbonate } \\
\text { bath }\end{array}$ \\
\hline \multirow{3}{*}{ Leaching } & \multirow{2}{*}{ I } & No & $3.0 \pm 0.2$ & $2.7 \pm 0.5$ & $2.1 \pm 0.4$ \\
& & Yes & $0.8 \pm 0.1$ & $2.2 \pm 0.0$ & $1.2 \pm 0.8$ \\
\cline { 3 - 6 } & \multirow{2}{*}{ II } & No & $3.3 \pm 0.1$ & $7.1 \pm 0.4$ & $8.0 \pm 0.2$ \\
& & Yes & $1.4 \pm 0.3$ & $24.1 \pm 2.5$ & $29.9 \pm 2.0$ \\
\hline \multirow{2}{*}{$\begin{array}{c}\text { Electro- } \\
\text { chemical }\end{array}$} & I & No & $26 \pm 5.2$ & $1090 \pm 30.2$ & $9 \pm 2.1$ \\
\cline { 2 - 6 } & II & No & $18 \pm 2.1$ & $380 \pm 25.1$ & $19 \pm 5.0$ \\
\hline
\end{tabular}

Dissolution of alloys resulted in the transfer of metals only to the electrolyte, since no slimes were formed on the samples' surfaces. Fig. 4 shows exemplary changes of metal ions (copper, zinc, lead) concentrations in the electrolytes during leaching. It was observed that some cations of metals forming soluble ammoniacal complexes were transferred to the solutions. It applied to copper, zinc and nickel ions, but not silver cations. Copper as a main component of the alloys was preferentially dissolved, and this was additionally affected by the initial pres- 
ence of $\mathrm{Cu}(\mathrm{II})$ ions. The latter was more distinct for the alloy II. It was quite surprised, since the second material contained less copper and lower percentages of copper-rich phases. However, comparison of the composition of the individual matrix phases suggests that high zinc percentage (17\%) in A and B phases of the alloy I inhibits copper dissolution from the brass. Moreover, less uniform distribution of zinc and tin enriched copper phases was observed in the first material. Dissolution of copper-rich phases was confirmed by changes of the zinc ions concentration. More preferential zinc leaching from the alloy II was found, but combination of the corrosive action of chloride ions and $\mathrm{Cu}$ (II) ions efficiently increased leaching of zinc.

Other metals, like silver and tin were not detected in the ammoniacal solutions, since they were present in the alloy as intermetallic phases resistant on the action of the electrolyte. Iron cannot be also dissolved, since it does not form soluble ammoniacal complexes [28].
Corrosion potentials of samples changed slightly from about $-0.07 \pm 0.05 \mathrm{~V}$ (vs. SCE) into more positive values at the initial period of leaching to the constant level closed to $0.15 \pm 0.02 \mathrm{~V}$ (vs. SHE). Such potential shift corresponded to the changes in the surface composition of the alloy. It allows monitoring the alloy dissolution - narrow range of the potential changes confirms that no slime layer formed on the samples surface, which could mechanically inhibit the process. However, constant levels of the final potential suggest that alloy matrix was dissolved spontaneously leaving intact refractory phases.

\subsection{Anodic dissolution of alloys}

The rate of the natural dissolution of the alloys in ammoniacal solutions was low. It was not advantageous for practical applications. Therefore, both alloys were dissolved electrochemi-
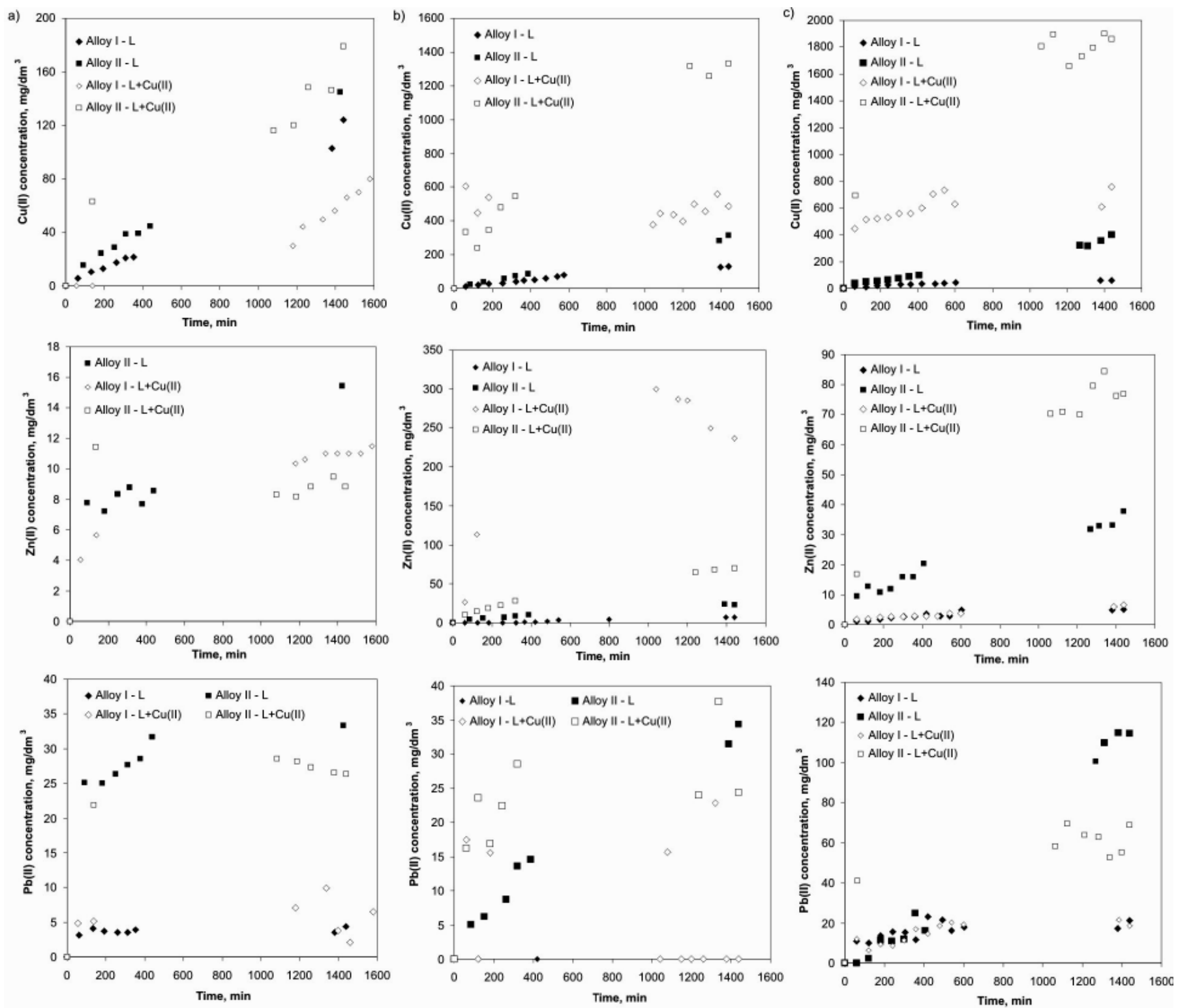

Fig. 4. Changes of $\mathrm{Cu}(\mathrm{II}), \mathrm{Zn}(\mathrm{II})$ and $\mathrm{Pb}(\mathrm{II})$ ions concentrations with the leaching time in ammoniacal solutions: a) sulfate, b) chloride, c) carbonate 
cally in the further series of experiments. Table 2 shows mass losses of the samples. Electrolysis seriously improved dissolution of the alloys, but the most aggressive conditions were found for the chloride solution.

During the process, metals were transferred to the electrolyte, cathodic deposit and slime or remained in the alloy. It was observed that anodic slime was not formed in sulfate and carbonate baths. This confirms that dissolved metals originated mainly from the soluble high copper matrix. More resistant phases remained in the anode structure, since ammonia as well as sulfate and carbonate ions were not enough aggressive for corrosion of lead, tin or silver bearing phases even under the current-flow conditions. However, in the chloride solution both alloys were seriously degraded and converted into precipitates with a mass corresponding to about $120 \%$ of the alloy mass loss. Fig. 5 shows $\mathrm{X}$-ray diffraction pattern of the "chloride-type" anodic slimes. It mainly consisted of chlorides and basic chlorides of copper and lead. Intermetallic phases originating from the alloys were also found. Some differences in the diffractograms suggest that the slimes originated from the alloy II consists of much smaller particles (as indicated by more broad ranges of some peaks), hence no all individual components could be identified.

Analysis of the metal contents in the slimes confirmed the presence of tin (about 40\%), lead (about 20\%) and copper (about $20 \%$ ) as well as some amounts of iron, zinc, silver and nickel.

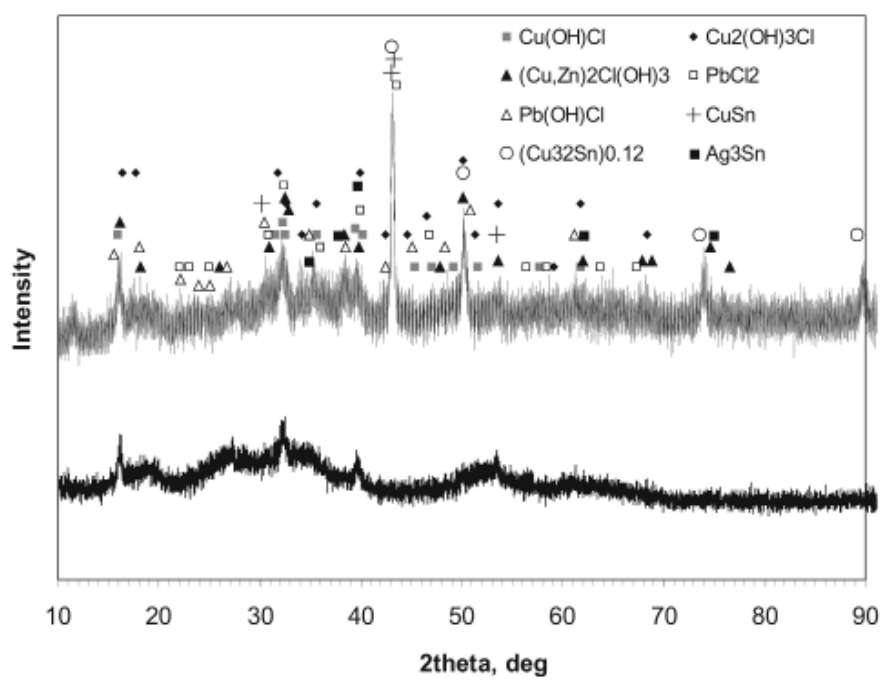

Fig. 5. Diffractograms of the anodic slimes formed in the chloride solution

Despite that high percentage of copper was found in the chloride-type slimes, the metal was favorably transferred to the electrolyte. Fig. 6 shows exemplary changes of metallic ions in the two baths during electrolysis. In all cases characteristic behavior was observed for copper: after about one hour a maximum of the concentration appeared. At longer time
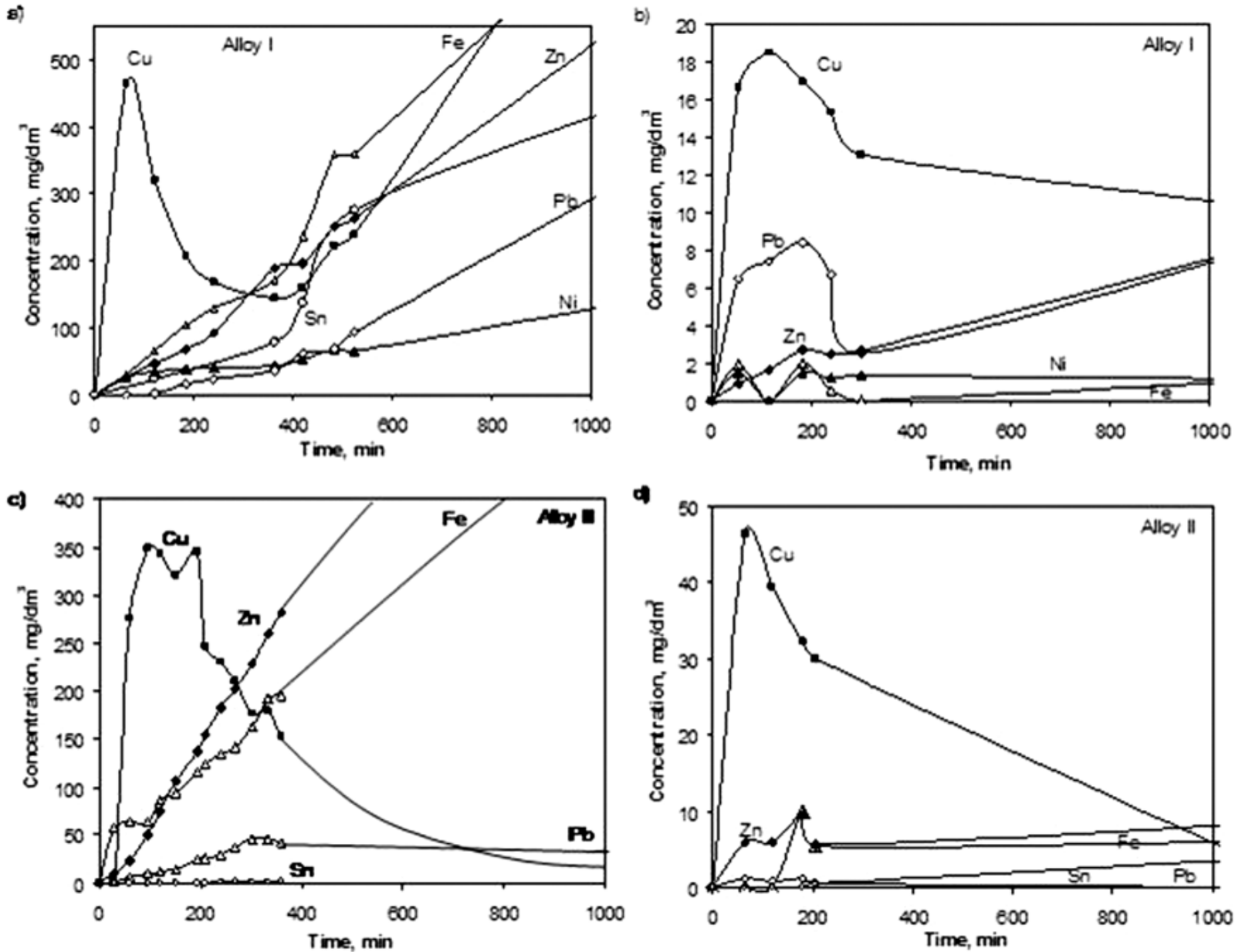

Fig. 6. Exemplary changes of metal ion concentration with electrolysis time: a, c) chloride solution, b,d) carbonate solution 
concentration of ions decreased due to deposition of copper on the cathode (Fig. 7). Content of other metals increased almost linearly (especially in chloride solutions, where particles of the slime were suspended in the bulk of the bath), but in carbonate or sulfate solutions their concentrations were much lower than for copper ions. It is worth to note that differences in the phase composition of the anodes and non-uniform distribution of the individual phases in the bulk of the samples resulted in the different dissolution rates of the particular metals. Such behavior was confirmed in independent measurements, but in all cases comparable final contents of metals transferred from the anode to the individual solutions were found (Table 3).

TABLE 3

Final concentrations of metals in the solutions after $24 \mathrm{~h}$ of electrolysis

\begin{tabular}{|c|c|c|c|c|c|c|}
\hline \hline \multirow{3}{*}{ Metal } & \multicolumn{6}{|c|}{ Concentration, mg/dm $^{3}$} \\
\cline { 2 - 7 } & \multicolumn{2}{|c|}{ Sulfate bath } & \multicolumn{2}{c|}{ Chloride bath } & \multicolumn{2}{c|}{ Carbonate bath } \\
\cline { 2 - 7 } & Alloy I & Alloy II & Alloy I & Alloy II & Alloy I & Alloy II \\
\hline $\mathrm{Cu}$ & 9 & 27 & 1067 & 60 & 8 & 0 \\
$\mathrm{Zn}$ & 44 & 34 & 895 & 118 & 12 & 11 \\
$\mathrm{Sn}$ & $\mathrm{nd}$ & $\mathrm{nd}$ & 482 & nd & nd & nd \\
$\mathrm{Ag}$ & $\mathrm{nd}$ & 1 & nd & 0 & 0 & 2 \\
$\mathrm{~Pb}$ & 4 & 2 & 410 & 19 & 4 & 1 \\
$\mathrm{Fe}$ & 7 & 1 & 879 & 35 & 1 & 6 \\
$\mathrm{Ni}$ & 0 & 0 & 166 & 20 & 2 & 0 \\
\hline
\end{tabular}

nd - not detected

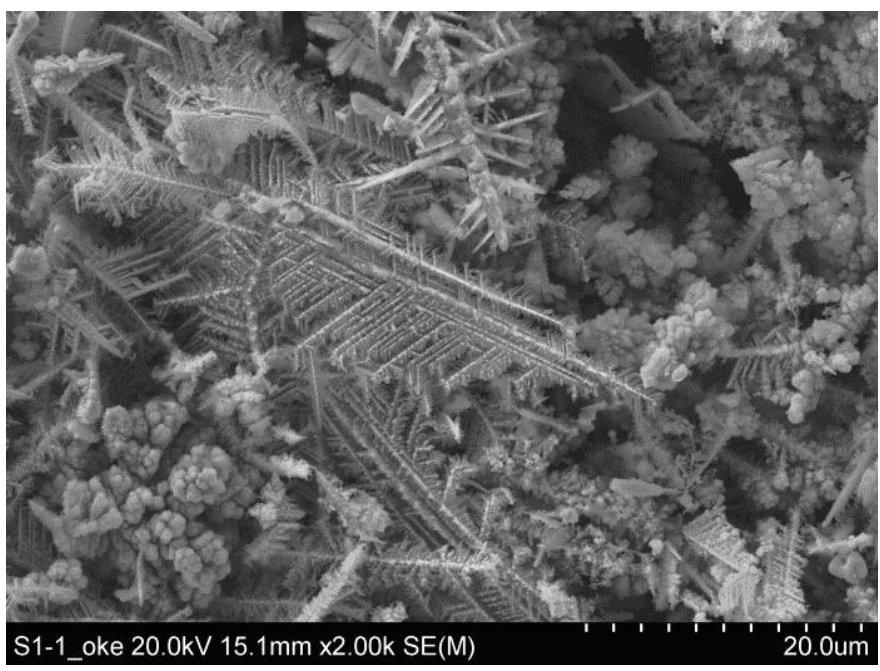

Fig. 7. Exemplary morphology of cathodic deposit

Copper deposited as powdery and dendritic deposits on the cathode due to low ions concentrations (Fig. 7). The purity of the cathodic deposits was high (99\%). Main contaminations were zinc $(0.1 \%)$ and silver (up to $0.1 \%)$. XRD analysis confirmed the presence of copper (Fig. 8), but some copper oxides were also formed due to secondary oxidation of the powder with the air. Cathodic current efficiency was very low, below $1 \%$.

Fig. 9 shows exemplary changes of the electrolysis voltage. For both alloys high and variable values of the voltage was registered in the chloride solutions: $3-4 \mathrm{~V}$ and up $9 \mathrm{~V}$ for alloys

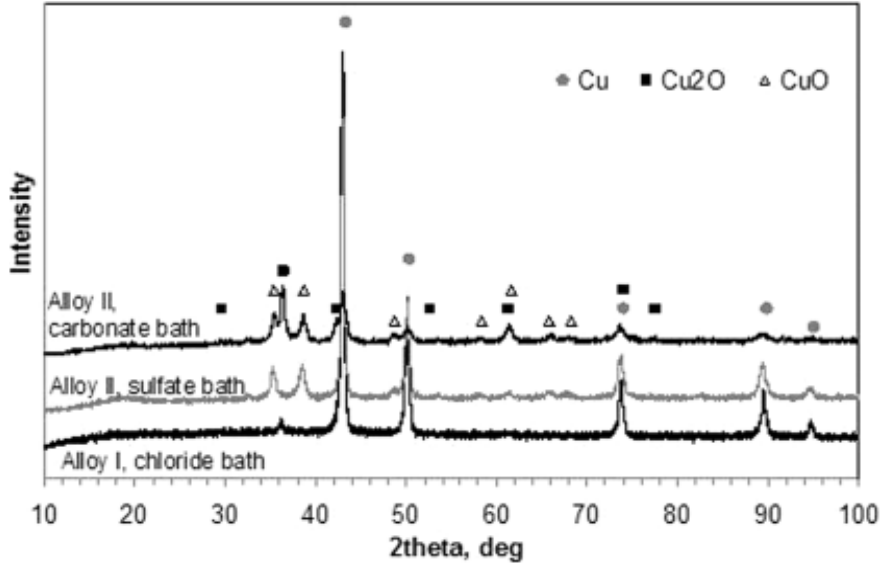

Fig. 8. XRD diffraction pattern of cathodic deposits

I and II, respectively. It was obvious, since slime formation on the anode could inhibit its dissolution. Electrolysis carried out in sulfate and carbonate solutions characterized with almost constant voltage about 2-3 V for alloy I and $3 \mathrm{~V}$ for alloy II.

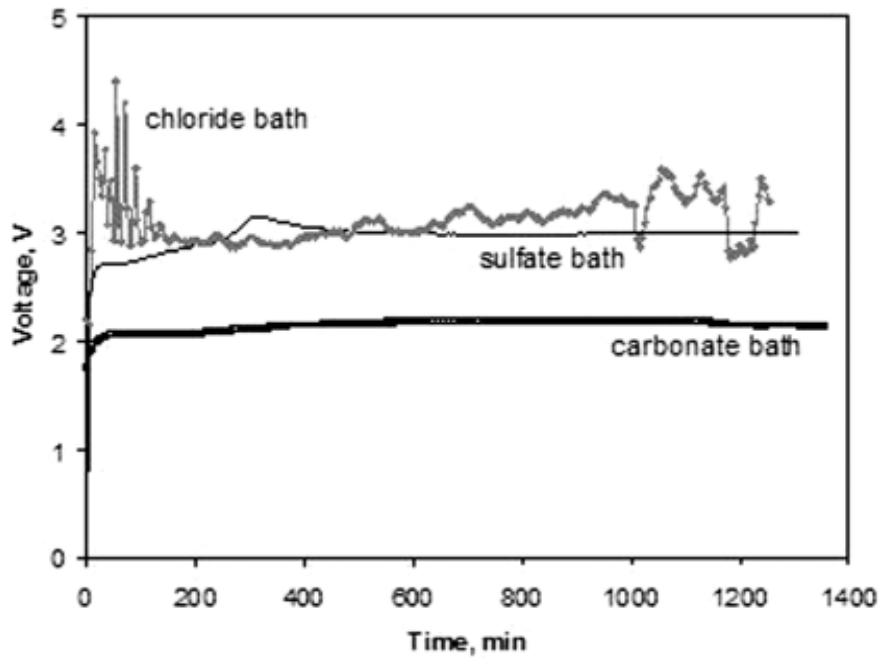

Fig. 9. Changes of electrolysis voltage during anodic dissolution of alloy $I$ in various solutions

\section{Conclusions}

Smelting of low grade electronic waste led to the formation of polymetallic and multiphase alloys containing 50-70\% of copper. Although similar phases were identified in the alloys, their fractions are dependent on the initial e-scrap composition. High copper content could suggest application of ammoniacal solution for selective copper dissolution from the material. However, the presence of zinc and tin in copper-rich phases inhibits such process.

Anodic dissolution of the alloys in ammoniacal solutions also is not advantageous for practical purposes. Separation of copper in electrolyte and cathode deposits was found, but amounts of the dissolved metal were still low. The most corrosive conditions were found for the ammoniacal-chloride system, where the alloys highly degraded into slimes containing chlorides 
1688

and basic chlorides of copper and lead. This forces further treatment of such chloride-type slimes.

Finally, comparison of the results obtained in this study and presented in the earlier papers $[23,24]$ confirms that the most benefit conditions for the electrochemical alloy treatment is application of acid sulfate-chloride electrolytes. Hydrometallurgical treatment of the alloys in the ammoniacal solutions, despite the expected fast autocatalytic selective copper dissolution, proved that complex phase compositions of the materials seriously complicate and inhibit the process.

\section{Acknowledgement}

This research work was supported by The National Centre for Research and Development (Poland) under grant no. INNOTECH-2/IN2/18/181960/ NCBR

\section{REFERENCES}

[1] T. Nakamura, K. Halada, Urban mining systems, 2015 Springer.

[2] C.P. Baldé, F. Wang, R. Kuehr, J. Huisman, The global e-waste monitor-2014, 2015 United Nations University IAS-SCYCLE, Bonn.

[3] F. Wang, J. Huisman, A. Stevels, C.P. Baldé, Waste Manage 33, 2397-2407 (2013).

[4] K. Breivik, J.M. Armitage, F. Wania, K.C. Jones, Environ. Sci. Technol. 48 (15), 8735-8743 (2014).

[5] E. Yamasue, R. Minamino, T. Numata, K. Nakajima, S. Murakami, I. Daigo, S. Hashimoto, H. Okumura, K.I. Ishihara, Mater. Trans. 50 (6), 1536-1540 (2009).

[6] A. Khalig, M.A. Rhamdhani, G. Brooks, S. Masood, Resources 3, 152-179 (2014)

[7] J. Cui, L. Zhang, J. Haz. Mater. 158, 228-256 (2008).

[8] A. Tuncuk, V. Stazi, A. Akcil, E.Y. Yazici, H. Deveci, Min. Eng. 25, 28-37 (2012).

[9] Z.H.I. Sun, Y. Xiao, J. Sietsma, H. Agterhuis, G. Visser, Y. Yang, Hydrometall. 152, 91-99 (2015).
[10] K. Koyama, M. Tanaka, J.-C. Lee, Mater. Trans. 47 (7), 1788-1792 (2006).

[11] T. Oishi, K. Koyama, S. Alam, M. Tanaka, J.-C. Lee, Hydrometall. 89, 82-88 (2007).

[12] A. Triphathi, M. Kumare, D.C. Sau, A. Agrawal, S. Chakravarty, T.R. Mankhand, Int. J. Metall. Eng. 1 (2), 17-21 (2012).

[13] C.J. Oh, S.O. Lee, H.S. Yang, T.J. Ha, M.J. Kim, J. Air Waste Manag. Associat. 53, 897-902 (2003).

[14] V.H. Ha, J. Lee, J. Jeong, H.T. Hai, M.K. Jha, J. Haz. Mater. 178, 1115-1119 (2010).

[15] K. Koyama, M. Tanaka, J.-C. Lee, Mater. Trans. 47 (8), 2076-2080 (2006).

[16] T. Oishi, K. Koyama, H. Konishi, M. Tanaka, J.-C. Lee, Electrochim. Acta 53, 127-132 (2007).

[17] T. Oishi, M. Yaguchi, K. Koyama, M. Tanaka, J.-C. Lee, Electrochim. Acta 53, 2585-2592, (2008)

[18] Y. Lim, O-k. Kwon, J. Lee, K. Yoo, Geosys. Eng. 16, 216-224 (2013).

[19] D.R. Groot, J.A.N. van der Linde, J. South. Afric. Inst. Min. Metall. 109, 697-700 (2009).

[20] R. Cayumil, R. Khanna, M. Ikram-Ul-Haq, R. Rajarao, A.V.S. Hill, Waste Manage. 34 (10), 1783-1792 (2014).

[21] R. Cayumil, R. Khanna, R. Rajarao, P.S. Mukherjee, V. Sahajwalla, Waste Manage. (2015), DOI: 10.1016/j.wasman.2015.12.004 (in press).

[22] E. Rudnik, M. Pierzynka, P. Handzlik, J. Mater. Cycl. Waste Manag. 18 (2), 318-328 (2016).

[23] E. Rudnik, K. Kołczyk, D. Kutyła, Trans. Nonferr. Met. Soc. Chin. 25 (8), 2763-2771 (2015).

[24] E. Rudnik, E. Bayaraa, Hydrometall. 159, 110-119 (2016).

[25] D.R. Groot, J.A.N. van der Linde, J. South. Afr. Inst. Min. Metall. 109, 701-707 (2009).

[26] I. de Marco, B.M. Caballero, M.J. Chomón, M.F. Laresgoiti, A.Torres, G. Fernández, S. Arnaiz, J. Anal. Appl. Pyrolysis 82, 179-183 (2008).

[27] J. Moltó, R. Font, A. Gálvez, J.A. Conesa, J. Anal. Appl. Pyrolysis 84, 68-78 (2009).

[28] R.P. Das, S. Anand, Hydrometall. 38, 161-173 (1995). 